\title{
Knowledge on HIV/AIDS and sexual behaviour among youths in Kibaha District, Tanzania
}

\author{
L.A.LEMA ${ }^{1 *}$, R.S.KATAPA ${ }^{2}$ and A.S.MUSA ${ }^{2}$ \\ ${ }^{1}$ Muhimbili Medical Research Centre, P.O. Box 3436, Dar es Salaam, Tanzania \\ ${ }^{2}$ University of Dar es Salaam, Department of Statistics , P. O. Box 35051, Dar es Salaam, Tanzania
}

\begin{abstract}
Sub-Saharan Africa is more heavily affected by HIV/AIDS than any other region in the World. Half of all new HIV infections occur in young people. Identification of the associated factors is likely to be useful in designing effective interventions. This cross-sectional study aimed to investigate the determinants of high-risk sexual behaviours among youths in Kibaha District, Tanzania. Data was collected using a structured questionnaire. The survey gathered data pertaining to the sexual healthy behaviours among youths, including condom use, number of sexual partners, age at first sexual involvement and knowledge on sexually transmitted diseases and HIV/AIDS. A total of 322 individuals aged 15-24 years were involved in the study. More than $69 \%$ had sex at least once in their life time. Only about one-third (32.3\%) of the youths reported to have used condom during the first sexual intercourse and $37 \%$ during the last sex. About $21.7 \%$ of the respondents acknowledged having more than one sexual partner in the last 12 months. The majority $(98.4 \%)$ of the respondents have heard of HIV/AIDS. About three quarters $(74.8 \%)$ of the respondents knew where to get HIV testing services but only a small proportion (28.9\%) had tested for HIV infection. Of those not yet tested, $38.2 \%$ admitted that they were ready to do so. Although 317 (98.4\%) respondents were aware of HIV/AIDS, and majority, $65.2 \%$ mentioned condom as the method used to prevent its transmission, only 117 (36.3\%) acknowledged using them. In conclusion, despite good knowledge on transmission of HIV among youths in Kibaha district, only a small proportion of them practices safe sex. Education programmes on safe sex practices should be strengthened to provide skills that could be effective in changing and maintaining safe sex behaviours among youths in Tanzania.
\end{abstract}

Keywords: HIV/AIDS, sexual behaviours, risk, youths, Tanzania

\section{Introduction}

An estimated 40 million people around the world are living with human immunodeficiency virus (HIV), whereby, young people (15-24 years old ) account for half of all new HIV infections worldwide (UNAIDS, 2004). More than five young people worldwide contract HIV every minute. At least $50 \%$ of young people are estimated to be sexually active by the age of 16 years (Eaton et al., 2003) and these are at a high risk of acquiring HIV infection. The nature of the causes and transmission of HIV/AIDS is complicated due to its being attributed to many factors such as biological, social, cultural and economical. HIV pandemic among the youths will have a great impact on human survival and development (UNAIDS, 2004). Sub-Saharan Africa is more heavily affected by HIV/AIDS than any other region of the world. An estimated 22.5 million people were living with HIV in 2007 and approximately 1.7 million people were expected to be infected with the virus during that year (UNAIDS, 2007). Tanzania had an estimated 1.6 million people living with HIV/AIDS as of the end of 2003 (UNAIDS, 2004). Although Tanzania prevalence rate is lower than some of the hardest hit countries in Sub-Saharan region, it is higher than the prevalence rate of the region overall (8.8\% compared to $7.5 \%)$ (UNAIDS, 2004).
The HIV/AIDS crisis is to a large extent a crisis of sexual behaviour. Unsafe sex is responsible for the large majority of the HIV infections in sub-Saharan Africa (WHO, 2002). Heterosexual contacts accounts for over $80 \%$ of HIV transmission in Tanzania $\mathrm{MoH}$, 1991; Barongo, 1992). Since the predominant mode of HIV infection in Tanzania is heterosexual, this in turn stimulated a strong belief that change of risky behaviour is a prevention and control measure for restricting the spread of the HIV.

According to recent surveys, the knowledge of AIDS is widespread in Tanzania, with $99 \%$ of the people having heard of the disease. Despite this high level of awareness and efforts made in fighting the disease through health education/promotion and care and treatment, the prevalence of HIV in is still high (THIS, 2005). Thus, increasingly youth's sexual involvement is becoming a subject of concern. Majority of youths engage in risk behaviours exposing them to unwanted pregnancies and sexually transmitted infections including HIV (Mwakagile, 2001). However, the factors underlying such risk behaviours are not well documented. Young people are the greatest hope for stopping the epidemic, partly because they are more likely than adults to adopt and maintain safe behaviour. This study was therefore undertaken to investigate the determinants of high-risk sexual behaviour among youth in Kibaha District, Tanzania in relation to their sexual practices. 


\section{Material and Methods}

\section{Study area}

This study was carried out in Kibaha District in eastern Tanzania. The district is located between latitude $6^{0} 6^{\prime}-7^{0} 05^{\prime} \mathrm{S}$ and longitudes $38^{0} 27^{\prime}-39^{\circ} 10^{\prime} \mathrm{E}$, most of the area lying at altitude below $100 \mathrm{~m}$. The district area is $1630 \mathrm{~km}^{2}$ and is divided into three divisions, nine wards and 25 villages. Kibaha has a population estimated at 136,402 of which males are 68,479 and females 67,923 , with a total of 30,417 households. The annual growth rate is estimated at $3.3 \%$. The majority of the inhabitants are small-scale farmers of cashew nuts, cassava, rice, simsim, fruits and vegetables. Some people also practice animal husbandry including cattle, goats and poultry farming.

\section{Study design and data collection}

This was cross sectional study which was conducted among youths aged between 15 and 24 years. Multistage cluster sampling design was employed to arrive at the household. The first stage involved selection of two wards. In each ward, all villages were listed to select two villages that had to be included in the survey. Then all households in the selected villages were listed and a random selection of households was done. From each of the selected households all eligible respondents were interviewed.

Interviews was done using a structured questionnaire to collect the desired information including; condom use, number of sexual partners, use of alcohol and drugs, age at first sexual involvement and knowledge on HIV/AIDS as well as willingness to test for the infection. Information of the status of circumcision among the males was explored.

\section{Data analysis}

Data was double entered and verified using EPI-Info version 6 software and analyzed using SPSS for windows software version 12. Basic description of the data frequency distribution, cross tabulation and other basic statistics were analyzed so as to determine relationship between the variables.

\section{Results}

A total of 322 youths aged between 15 and 24 years (mean age of 19.4 years) were interviewed. Overall, the majority, $210(65.2 \%)$ were males and 56.8\% of the respondents were Moslems. About one-third (31.1\%) had attained secondary education, 54.3\% had completed primary education while $14.6 \%$ had no formal education. Two hundred and four (63.4\%) respondents were working in public services, farming or privately employed while $118(36.6 \%)$ were students. Out of all respondents, 269 (83.5\%) were single, $51(15.8 \%)$ were married/cohabited (living with a partner), the rest were divorced. Among those who were married, 33 (64\%) got married before age of 20 whereas $14(42.4 \%)$ were males and $19(57.6 \%)$ females. The median age at first marriage for female was 20 years (Figure 1).

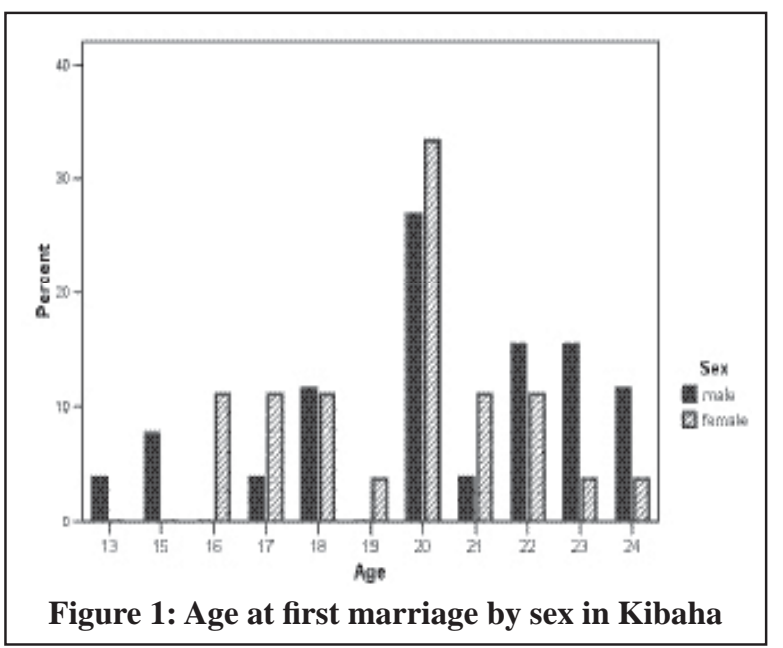

The findings showed that, $228(70.8 \%)$ had sexual intercourse at least once in their lifetime (156 (68.4\%) and $72(31.6 \%)$ for males and females respectively). Six of the respondents did not indicate whether they had sexual intercourse or not. It was also found that, $29.2 \%$ of females and $35.9 \%$ of males had sex before the age of 15 years. The mean age at which girls had lost their virginity was 16.3 years. Age at first sex varied between respondents (Table 1). Those with a lower age (15-19 years) started sexual affairs at an earlier age compared to those at older age. Similarly a large number of students involved themselves in sexual matters at a younger age.

A total of 71 youths who had sex 12 months prior to the survey had more than one sexual partner. Of these, $53(74.6 \%)$ and $18(25.4 \%)$ were males and females, respectively). Only about one-third (32.3\%; $\mathrm{N}=104$ ) reported to have used condom during the first sexual intercourse and 117 (36.3\%) during the last act (Table 2)

The reasons for not using condoms were as follows: $44(13.7 \%)$ were not aware of condoms, $26(8.1 \%)$ did not know if it was important and 20 $(6.2 \%)$ said the partner rejected. Respondents were asked if they had ever heard of HIV/AIDS. A total of $317(98.4 \%)$ were aware of the disease and 289 
Table 1: Variation of age at first sex between youths in Kibaha

\begin{tabular}{|c|c|c|c|c|}
\hline \multirow[t]{2}{*}{ Variable } & \multirow[t]{2}{*}{ Category } & \multicolumn{3}{|c|}{ Age at first sex (years) } \\
\hline & & $\leq 15$ & $\geq 16$ & $\chi^{2}$ \\
\hline \multirow[t]{2}{*}{$\overline{\mathrm{Age}}$} & $15-19$ years & 43 & 41 & \multirow[b]{2}{*}{$17.625^{\star}$} \\
\hline & $20-24$ years & 35 & 111 & \\
\hline \multirow[t]{2}{*}{ Sex } & Male & 56 & 100 & \multirow[b]{2}{*}{1.264} \\
\hline & Female & 21 & 51 & \\
\hline \multirow[t]{3}{*}{ Occupation } & Students & 26 & 24 & \multirow{3}{*}{$9.326^{*}$} \\
\hline & Workers & 52 & 128 & \\
\hline & Muslims & 51 & 84 & \\
\hline \multirow[t]{2}{*}{ Religion } & Christians & 26 & 68 & 2.542 \\
\hline & Single & 65 & 113 & \multirow[b]{2}{*}{2.382} \\
\hline Marital status & Married/Cohabited & & & \\
\hline
\end{tabular}

${ }^{*}$ Significant at $5 \%\left(\chi^{2}=3.841\right)$

$(89.1 \%)$ have heard/seen over the radio or television, 229 (71.1\%) had read HIV/AIDS from newspapers. However, four $(1.2 \%)$ of the respondents had never heard of HIV/AIDS. The majority of the respondents $(81.4 \%$; $\mathrm{N}=262)$ agreed that, it was possible to prevent oneself from getting HIV/AIDS infection, mainly through the use of condom (65.2\%), abstaining from sex $(37.6 \%)$ and $(14.6 \%)$ by having a single faithful partner who had been tested for HIV.

Interestingly, 290 (90.1\%) respondents knew where attending voluntary counselling and testing centres were to know their status $(19.9 \%)$ and a requirement during antenatal clinic (7.1\%). A total of $123(38.2 \%)$ of the respondents were ready to be tested for HIV. It was also found that $23.6 \%$ of the males and $17.9 \%$ of female were using alcohol.

\section{Discussion}

Consistent with other studies, early age at first intercourse was associated with young peoples having

Table 3: Condom use by sex among youth in Kibaha

\begin{tabular}{lccc}
\hline Sex of the respondent & $\begin{array}{l}\text { Condom use (Yes) } \\
\text { During the first sexual } \\
\text { intercourse }\end{array}$ & $\begin{array}{l}\text { During the last sexual } \\
\text { intercourse }\end{array}$ & Total $^{*}$ \\
\hline Males & $75(47.5 \%)$ & $83(52.5 \%)$ & 158 \\
Females & $29(46.0 \%)$ & $34(54.0 \%)$ & 63 \\
Total & 104 & 117 & 221 \\
\hline
\end{tabular}

*Some respondents used a condom during both sexual encounters

to obtain male's condom and the places mentioned frequently included shops $(82.9 \%)$ and pharmacies $(47.2 \%)$. A large proportion of the respondents $(71 \%$; $\mathrm{N}=209$ ) had heard of female's condom but only 19 $(5.9 \%)$ had used them. The majority $(91.6 \% ; \mathrm{N}=295)$ of the respondents had heard information on sexually transmitted diseases (STDs) related to HIV/AIDS though were unable to describe correctly their symptoms. About three-quarters ( $74.8 \%$ ) of the respondents knew where to receive HIV testing services and 93 $(28.9 \%)$ have sought the service. The reasons for multiple partners and is a risk marker for sexual behaviours (Greenberg, 1992; Eaton et al., 1992; Seidman et al., 1992). Moreover, since early age of marriage was thought to be an important factor for exposure of women and men to sexual intercourse and a leading mechanism for HIV infection in Tanzania, it is also a primary indicator of exposure to the STDs and other risk associated with early pregnancy. Having multiple partners increases the risk of acquiring sexually transmitted infections. Those having more than one sexual partner were considered to be at higher risk (THIS 


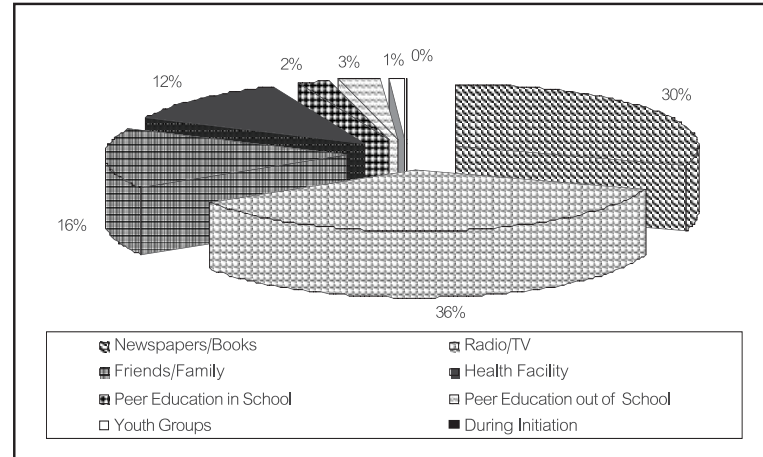

Figure 2: Sources of information about HIV/AIDS reported by youths in Kibaha

2005). Males reported to have more multiple sexual partners than females, this findings was consistent with findings from the study by Smith (1989).

Participants were aware of dangers of HIV/AIDS including knowledge on how it can be contracted and how one can protect oneself. Recent surveys have reported that at least $95 \%$ of Tanzanians, regardless of their background characteristics, have heard of HIV/AIDS (TDHS, 2005); however, comprehensive knowledge of HIV transmission and prevention was slightly lower among young people (15-24 years). In another study in western Tanzania, Nkya et al. (2006) reported that although the knowledge on AIDS as a disease and its prevention was high, there were gaps on the linkage of knowledge on modes of transmission and preventative measures. Similarly, in our study, many youths were not putting their knowledge into practice, with only a third of the respondents reported using condom during their first sexual intercourse. Results of this study are consistency with those of Mutakar \& Hemant, (1999) in India. The authors reported that Indian adolescents, particularly males are sexually active and are likely to indulge in unsafe sexual activities making them vulnerable to STDs including HIV. In a recent study in western Tanzania, the majority of youths were reported to start practising sex from the age of 16 years (Nkya et al., 2006).

In this survey although majority of the youths were knowledgeable on where to seek for HIV test services, only a small proportion $(28.9 \%)$ have tested and only one third were ready to test. In Tanzania, only about $14 \%$ of the population have ever been tested by 2004 (TDHS, 2005), and that people in urban areas are more likely than those in rural areas to have been tested. The number of those tested is likely to have increased markedly in recent years following the launching of a nation-wide HIV testing campaign. Knowledge on where to go for the HIV test and availability of test services increases the probability of testing (THIS, 2005).

Some of the limitations of this study were that the research was designed as a behavioural surveillance tool, and not as a method of providing in-depth information about a particular behaviour, thus offer little information about peer norms or factors such as self-efficacy that may influence decision-making about sexual partner. Self-reported sexual behaviour is difficult to validate. Sampling unit of this study was a household. Some household visited had no youth within the specified age group (i.e. 15-24 years). In other households youths were out for their holiday as the school/college was closed.

In conclusion, although knowledge about HIV was high among the participants, the proportion of those using condoms is low. Moreover, having multiple sexual partners and sexual practices at lower age are common among the study population. It is therefore, important that safe sex practices are advocated to youths to provide skills that could be effective in changing and maintaining safe sex behaviours. Moreover, there should be a comprehensive sexual and behavioural survey among young people for testing HIV. This will provide the current demographic data on HIV prevalence among youths in Tanzania and thus bring proper interventions for combating HIV and other related infections. Youth education on safe sex, condom use and other protective methods should also be strengthened and to include both rural and urban populations.

\section{Acknowledgements}

We wish to acknowledge the District Commissioner, District Executive Director of Kibaha District for facilitating this study. We are grateful to Dr. Geoffrey Somi of the National AIDS Control Programme and Drs Amos Kahwa and Ester Ngadaya of the National Institute for Medical Research for their comments on the earlier version of this manuscript. This study received financial assistance from the National Institute for Medical Research.

Received 20 August 2007

Revised 25 March 2008

Accepted 26 March 2008 


\section{References}

Barongo, L.R., Rugemalila, J.B., Gabone, R.M. \& Senkoro, K.P. (1992) Kagera 1989 health survey: Human immunodeficiency virus seroprevalence in adolescents. East African Medical Journal 69, 323-326.

Eaton, L., Flisher, A.J. \& Aaro, L.E. (2003) Unsafe sexual behaviour in South African youth. Social Science and Medicine $56,149-165$.

Greenberg, J. (1992). Age at first sex coitus: a marker of risky sexual behaviour in women. Sexually Transmitted Diseases 19, 331-334.

MoH (1991) HIV/AIDS/STD Surveillance Report No.4. National AIDS Control Programme, Ministry of Health, Dar es Salaam, Tanzania.

Mutakar, R. \& Hemant, A. (1999) Sexual Behaviour amongst adolescence in rural western Maharashtra. Aids Research and Review 12, 89-94.

Mwakagile, D., Mmary, E., Makwaya, C., Mbwana, J., Biberfeld, G. \& Mhalu, F. (2001) Sexual behaviour among youths at high risk for HIV-1 infection in Dar es Salaam. Sexual Transmitted Infections 77, 255-259.

Nkya G.M., Sindato, C., Mcharo, J. \& Kibona S.N. (2006) Community knowledge on HIV/
AIDS and its relationship with sexual practices in Tabora and Igunga District, western Tanzania. Tanzania Health Research Bulletin 8, 173-176.

Seidman, S., Moshr, W. \& Aral, S. (1992) Women with multiple sexual partners: United States, American Journal of Public Health 82, 1388-1394

Smith, T. (1989) Adult sexual behaviour in: number of partners, frequency of intercourse and risk of AIDS. Family Planning Perspective 23, 102-107.

THIS (2005) 2003-2004 Tanzania HIV/AIDS Indicator Survey. Tanzania Commission for AIDS, National Bureau of Statistics, ORC Macro, March 2005

TDHS (2005) Tanzania Demographic and Health Survey 2004-05. Dar es Salaam, Tanzania: National Bureau of Statistics and ORC Macro, December 2005

UNAIDS (2004) Report on the Global AIDS Epidemic $20044^{\text {th }}$ Global Report (UNAIDS /04/16E). Geneva, Switzerland: UNAIDS

UNAIDS (2007) AIDS Epidemic Update. World Health Organization, Geneva. UNAIDS/ 07.27E/JC1322E.

WHO (2002) The World Health Report 2002. Reducing Risks, Promoting Healthy Life. World Health Organization. Geneva, 248 pp. available at: http//: www.who. int/whr/2002/ (Accessed August 20, 2003). 